\title{
Organic Polymers as Porogenic Structure Matrices for Mesoporous Alumina and Magnesia
}

\author{
Zimei Chen ${ }^{1,2}$, Christian Weinberger ${ }^{1}$, Michael Tiemann ${ }^{1, *}$ and Dirk Kuckling ${ }^{2, *}$ \\ 1 Department of Chemistry-Inorganic Functional Materials, University of Paderborn, Warburger Str. 100, \\ 33098 Paderborn, Germany; zimei.chen@uni-paderborn.de (Z.C.); \\ christian.weinberger@uni-paderborn.de (C.W.) \\ 2 Department of Chemistry-Organic and Macromolecular Chemistry, University of Paderborn, \\ Warburger Str. 100, 33098 Paderborn, Germany \\ * Correspondence: michael.tiemann@uni-paderborn.de (M.T.); dirk.kuckling@uni-paderborn.de (D.K.)
}

Received: 10 October 2017; Accepted: 6 November 2017; Published: 8 November 2017

\begin{abstract}
Mesoporous alumina and magnesia were prepared using various polymers, poly(ethylene glycol) (PEG), poly(vinyl alcohol) (PVA), poly(N-(2-hydroxypropyl) methacrylamide) (PHPMA), and poly(dimethylacrylamide) (PDMAAm), as porogenic structure matrices. Mesoporous alumina exhibits large Brunauer-Emmett-Teller (BET) surface areas up to $365 \mathrm{~m}^{2} \mathrm{~g}^{-1}$, while mesoporous magnesium oxide possesses BET surface areas around $111 \mathrm{~m}^{2} \mathrm{~g}^{-1}$. Variation of the polymers has little impact on the structural properties of the products. The calcination of the polymer/metal oxide composite materials benefits from the fact that the polymer decomposition is catalyzed by the freshly formed metal oxide.
\end{abstract}

Keywords: mesoporous alumina; mesoporous magnesia; poly(ethylene glycol); poly(vinyl alcohol); poly(N-(2-hydroxypropyl) methacrylamide); poly(dimethylacrylamide)

\section{Introduction}

Mesoporous metal oxides with large specific surface areas and uniform pore sizes have recently attained great interest, particularly regarding potential applications in such areas as catalysis [1], energy conversion and storage [2], and gas sensing [3,4]. By definition, mesopore widths range from 2 to $50 \mathrm{~nm}$ [5]. For metal oxides with uniform and ordered mesopores, a variety of synthesis methods have been established, mostly by utilization of porogens; said porogens may be supramolecular entities of amphiphilic species dispersed in liquid media ('soft templates' [6]) or solid structure matrices such as porous silica ('hard templates') in the so-called 'nanocasting' process [6-9].

Alumina (aluminum oxide, $\mathrm{Al}_{2} \mathrm{O}_{3}$ ) and magnesia (magnesium oxide, $\mathrm{MgO}$ ) with high surface-to volume ratios play an important role as catalyst/catalyst support materials [10-13] and as adsorbents [14-16]. Both materials can be prepared by nanocasting, which leads to ordered and uniform mesopores. However, unlike for most other metal oxides, mesoporous silica is not suitable as a structure matrix here, because its removal requires chemical etching under strongly basic (e.g., $\mathrm{NaOH})$ or acidic (HF) conditions. Both $\mathrm{Al}_{2} \mathrm{O}_{3}$ and $\mathrm{MgO}$ are amphoteric oxides that cannot withstand these conditions. Instead, mesoporous carbon materials have been employed as structure matrices for amphoteric oxides such as mesoporous $\mathrm{Al}_{2} \mathrm{O}_{3}[17,18], \mathrm{MgO}[19,20]$, and $\mathrm{ZnO}[21-24]$, since their removal can be accomplished under milder condition by thermal oxidation $[25,26]$. Likewise, organic hydrogels have also been shown to be versatile porogenic matrices for porous oxidic materials [27-31]. We have recently described the utilization of photo cross-linked poly(dimethylacrylamide)-based hydrogels $[32,33]$ as matrices for mesoporous alumina [34,35]. Here we report on the utilization of non-cross-linked water-soluble polymers as porogenic species for mesoporous $\mathrm{Al}_{2} \mathrm{O}_{3}$ and $\mathrm{MgO}$; the synthesis process is thus simplified. 
Polymer chains begin to overlap and form entanglements when the polymer solution is above a critical concentration. Hence, a physical network is formed between different polymer chains in a concentrated solution [36,37]. Therefore, a concentrated polymer solution could also theoretically work as a structure matrix to prepare mesoporous metal oxides. In this paper, we describe the synthesis of mesoporous alumina and magnesium oxide using simple polymers, such as poly(ethylene glycol) (PEG), poly(vinyl alcohol) (PVA), poly(N-(2-hydroxypropyl) methacrylamide) (PHPMA), and poly(dimethylacrylamide) (PDMAAm), as matrices. The strategy proposed here to prepare porous alumina and magnesium oxide is based on a one-pot synthesis approach using saturated aluminum/magnesium nitrate as precursor solutions and introducing direct polymers.

\section{Materials and Methods}

\subsection{Materials}

Poly(ethylene glycol) (PEG, Fluka, Darmstadt, Germany, $\mathrm{M}_{\mathrm{n}} 6000 \mathrm{~g} \mathrm{~mol}^{-1}$ ), poly(vinyl alcohol) (PVA, Acros, Geel, Belgium, $\geq 98 \%, \mathrm{M}_{\mathrm{n}} 16,000 \mathrm{~g} \mathrm{~mol}^{-1}$ ), aluminum nitrate nonahydrate (Sigma-Aldrich, Darmstadt, Germany, $\geq 98.0 \%$ ), magnesium nitrate hexahydrate (Sigma-Aldrich, Darmstadt, Germany, $\geq 97 \%$ ), 1-amino-2-propanol (TCI, Eschborn, Germany, >98\%), methacryloyl chloride (Fluka, Darmstadt, Germany, >97\%), and 1,2-diaminoethane (Acros, Geel, Belgium, >99\%) were used as received. N,N-dimethylacrylamide (DMAAm, TCI, Eschborn, Germany, 99\%) was distilled under low pressure. $\alpha, \alpha^{\prime}$-Azobisisobutyronitrile (AIBN, Fluka, Darmstadt, Germany, $>98 \%$ ) was recrystallized from methanol. Ammonia solution (Stockmeier, Bielefeld, Germany, 25\%), diethyl ether (Hanke + Seidel, Steinhagen, Germany), tetrahydrofuran (THF, BASF, Ludwigshafen, Germany), 1,4-dioxane (Carl Roth, Karsruhe, Germany, $\geq 99.5 \%$ ) ethyl acetate (Stockmeier, Bielefeld, Germany,), methanol (Stockmeier, Bielefeld, Germany,), magnesium sulfate (Grüssing, Filsum, Germany, 99\%), acetone (Stockmeier, Bielefeld, Germany,), and sodium sulfate (Grüssing, Filsum, Germany, 99\%) were used as received.

\subsection{Characterization}

${ }^{1} \mathrm{H}$ and ${ }^{13} \mathrm{C}$ NMR spectra were recorded on a Bruker (Billerica, Massachusetts, USA) AV 500 spectrometer at $500 \mathrm{MHz}$ and $125 \mathrm{MHz}$, respectively. Reference solvent signals at 7.26 and $2.56 \mathrm{ppm}$ were used for spectra in $\mathrm{CDCl}_{3}$ (99.8 atom-\% Deuterium) and DMSO-d $\mathrm{d}_{6}\left(\mathrm{O}=\mathrm{S}\left(\mathrm{CD}_{3}\right)_{2}\right.$, $99.9 \%)$, respectively.

Gel permeation chromatography (GPC) was performed in chloroform for PEG and PDMAAm at $30{ }^{\circ} \mathrm{C}$ and at a flow rate of $0.75 \mathrm{~mL} \mathrm{~min}^{-1}$ on a Jasco (Groß-Umstadt, Germany) 880-PU Liquid Chromatograph connected to a Shodex (Yokohama, Japan) RI-101 detector. The instrument was equipped with four consecutive columns (PSS-SDV columns filled with $5 \mu \mathrm{m}$ gel particles with a defined porosity of $10^{6} \AA, 10^{5} \AA, 10^{3} \AA$, and $10^{2} \AA$, respectively), and both samples were calibrated by poly(methyl methacrylate) standards. GPC was performed in hexafluoroisopropanol for PVA at $0{ }^{\circ} \mathrm{C}$

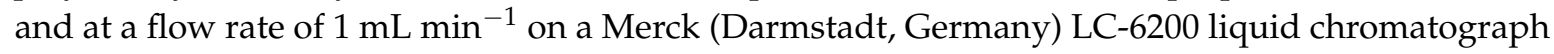
connected to a Shodex (Yokohama, Japan) RI-101 detector. The instrument was equipped with a PSS-PFG $10^{3} \AA$ and PSS-PFG $10^{2} \AA$ column, and the sample was calibrated by poly(methyl methacrylate) standards. GPC was performed in $N, N$-dimethylacetamide for PHPMA at $50{ }^{\circ} \mathrm{C}$ and at a flow rate of $0.5 \mathrm{~mL} \mathrm{~min}^{-1}$ on a Merck (Darmstadt, Germany) LC 655A-11 liquid chromatograph connected to a Waters (Milford, Massachusetts, United States) RI 2410 detector. The instrument was equipped with PSS-GRAM $10^{4} \AA$, PSS-GRAM $10^{3} \AA$, and PSS-GRAM $10^{2} \AA$ columns, and the sample was calibrated by poly(methyl methacrylate) standards. Thermogravimetric analysis (TGA) was conducted under synthetic air at a heating rate of $10{ }^{\circ} \mathrm{C} \mathrm{min}-1$ using a Mettler Toledo (Columbus, Ohio, USA) TGA/SDTA851. $\mathrm{N}_{2}$ physisorption analysis was performed at $77 \mathrm{~K}$ on a Quantachrome (Boynton Beach, Florida, United States) Autosorb 6B instrument; samples were degassed at $120{ }^{\circ} \mathrm{C}$ for $12 \mathrm{~h}$ prior to measurement. Specific surface areas were assessed via multi-point Brunauer-Emmett-Teller 
(BET) analysis [38] in the range of $0.1 \leq p / p_{0} \leq 0.3$. Pore volumes were calculated at $p / p_{0}=0.99$. Pore size distributions were calculated via Barrett-Joyner-Halenda (BJH) analysis [39] from the desorption branches of the isotherms. Powder X-ray diffraction was performed with a Bruker (Billerica, Massachusetts, USA) AXS D8 Advance diffractometer with $\mathrm{Cu} \mathrm{K} \alpha$ radiation $(40 \mathrm{kV}, 40 \mathrm{~mA})$ with a step size of $0.02^{\circ}$ and a counting time of $3 \mathrm{~s}$ per step.

\subsection{Monomer Synthesis}

$\mathrm{N}$-(2-hydroxypropyl) methacrylamide (HPMA) was synthesized as described in the literature [40]. 1-Amino-2-propanol $(45.5 \mathrm{~mL}, 589 \mathrm{mmol})$ and ethyl acetate $(450 \mathrm{~mL})$ were added in a $1 \mathrm{~L}$ three-neck round-bottom flask equipped with addition funnel. The flask was cooled to $10{ }^{\circ} \mathrm{C}$ and purged with argon for $15 \mathrm{~min}$. Methacryloyl chloride $(28 \mathrm{~mL}, 287 \mathrm{mmol})$ and ethyl acetate $(50 \mathrm{~mL})$ were added to the addition funnel and purged with argon for 15 min and left under an argon atmosphere. The methacryloyl chloride/ethyl acetate mixture was then added dropwise to the 1-amino-2-propanol/ethyl acetate mixture. The mixture was reacted in an ice bath for $1 \mathrm{~h}$. Afterwards, the mixture was washed three times with an aqueous sat. sodium sulfate solution $(250 \mathrm{~mL})$ in a separatory funnel to remove any excess of reactants and side products. The aqueous phase was discarded and the organic phase was dried over magnesium sulfate and concentrated in vacuo to approximately $50 \mathrm{~mL}$. The concentrate was then allowed to age for $1 \mathrm{~h}$ at $10{ }^{\circ} \mathrm{C}$. The product was collected as colorless solid by filtration, dried under vacuum, and stored in the freezer. $(11.52 \mathrm{~g}, 28 \%)$ ${ }^{1} \mathrm{H}$ NMR $\left(500 \mathrm{MHz}, \mathrm{CDCl}_{3}\right): \delta(\mathrm{ppm})=1.21\left(\mathrm{~d}, J=6.3 \mathrm{~Hz}, 3 \mathrm{H},=\mathrm{CCH}_{3}\right), 1.97(\mathrm{dd}, J=1.5,1.0 \mathrm{~Hz}$, $\left.3 \mathrm{H},(\mathrm{HO}) \mathrm{CCH}_{3}\right), 2.36(\mathrm{~s}, 1 \mathrm{H}, \mathrm{OH}), 3.18\left(\mathrm{ddd}, J=14.0,7.6,5.2 \mathrm{~Hz}, 1 \mathrm{H}, \mathrm{CH}_{2}\right), 3.51(\mathrm{ddd}, J=14.0,6.5$, $\left.3.0 \mathrm{~Hz}, 1 \mathrm{H}, \mathrm{CH}_{2}\right), 3.96(\mathrm{ddd}, J=7.6,6.3,3.0 \mathrm{~Hz}, 1 \mathrm{H}, \mathrm{CH}), 5.33-5.37\left(\mathrm{~m}, 1 \mathrm{H},=\mathrm{CH}_{2}\right), 5.69-5.74(\mathrm{~m}, 1 \mathrm{H}$, $\left.=\mathrm{CH}_{2}\right), 6.24$ (br. s, $\left.1 \mathrm{H}, \mathrm{NH}\right) .{ }^{13} \mathrm{C} \mathrm{NMR}\left(125 \mathrm{MHz}, \mathrm{CDCl}_{3}\right): \delta(\mathrm{ppm})=18.64\left(\mathrm{CH}_{3}\right), 21.04\left(\mathrm{CH}_{3}\right), 47.17$ $\left(\mathrm{NH}-\mathrm{CH}_{2}\right), 67.52(\mathrm{CH}-\mathrm{OH}), 119.88\left(=\mathrm{CH}_{2}\right), 139.77(=\mathrm{C}), 169.39(\mathrm{C}=\mathrm{O})$.

\subsection{Polymer Synthesis}

Homopolymer PDMAAm was synthesized by free radical polymerization initiated with AIBN as described in the literature [41]. Monomer DMAAm ( $5.2 \mathrm{~mL}, 50.4 \mathrm{mmol})$ and AIBN (10 mg, $0.06 \mathrm{mmol})$ were dissolved in 1,4-dioxane $(92 \mathrm{~mL})$ and purged with argon for $20 \mathrm{~min}$. The polymerization was carried out at $70{ }^{\circ} \mathrm{C}$ for $7 \mathrm{~h}$ under an argon atmosphere. Afterwards, the polymer was precipitated in diethyl ether and reprecipitated from THF into diethyl ether for the purification. Finally, the product was obtained by low pressure drying and characterized by NMR spectroscopy and GPC (see Table 1 ). $(3.39 \mathrm{~g}, 68 \%){ }^{1} \mathrm{H}$ NMR $\left(500 \mathrm{MHz}, \mathrm{CDCl}_{3}\right): \delta(\mathrm{ppm})=1.51-1.83\left(\mathrm{~m}, \mathrm{CH}_{2}\right), 2.30-2.74(\mathrm{~m}, \mathrm{CH}), 2.75-3.22$ $\left(\mathrm{m}, \mathrm{CH}_{3}\right)$.

Homopolymer PHPMA was synthesized by free radical polymerization initiated with AIBN as described in the literature [42]. Monomer HPMA (1.5 g, $10.5 \mathrm{mmol})$ and AIBN (1.7 mg, $0.010 \mathrm{mmol})$ were dissolved in 1,4-dioxane $(20 \mathrm{~mL})$ in a $50 \mathrm{~mL}$ nitrogen flask and was degassed three times by freeze/thaw cycles. The HPMA was polymerized at $65{ }^{\circ} \mathrm{C}$ for $8 \mathrm{~h}$ under an argon atmosphere. The mixture was poured into acetone to get a white solid, which was collected and washed with acetone repeatedly. Further purification was carried out by dissolving the polymer in methanol and precipitating into acetone. The product was collected and dried under vacuum to obtain the homopolymer as a white powder and characterized by NMR spectroscopy and GPC (see Table 1). $(1.16 \mathrm{~g}, 77 \%){ }^{1} \mathrm{H}$ NMR $(500 \mathrm{MHz}, \mathrm{DMSO}): \delta(\mathrm{ppm})=0.70-1.13\left(\mathrm{~m}, \mathrm{CH}_{3}\right), 1.43-2.04\left(\mathrm{~m}, \mathrm{CH}_{2}\right), 2.92(\mathrm{~m}$, $\left.\mathrm{NH}-\mathrm{CH}_{2}, \mathrm{OH}\right), 3.69\left(\mathrm{~m}, \mathrm{NH}-\mathrm{CH}_{2}\right), 4.69(\mathrm{~m}, \mathrm{CH}), 7.14(\mathrm{br}, \mathrm{NH})$. 
Table 1. Characterization of the used homopolymers.

\begin{tabular}{cccc}
\hline Polymer & $\boldsymbol{M}_{\boldsymbol{n}} /\left(\mathrm{g} \mathrm{mol}^{-\mathbf{1}}\right)$ & D & Yield/\% \\
\hline PEG $^{1}$ & 12,000 & 1.1 & - \\
PVA $^{1}$ & 23,000 & 2.4 & - \\
PDMAAm $^{1}$ & 26,000 & 2.8 & 68 \\
PHPMA $^{1}$ & 43,000 & 6.3 & 77
\end{tabular}

1 Poly(ethylene glycol) (PEG) and poly(dimethylacrylamide) (PDMAAm) determined by gel permeation chromatography (GPC) in $\mathrm{CHCl}_{3}$, poly(vinyl alcohol) (PVA) determined in hexafluoroisopropanol, and poly( $\mathrm{N}-(2-$ hydroxypropyl) methacrylamide) (PHPMA) determined in $N, N$-dimethylacetamide, all of which were calibrated by poly(methyl methacrylate) (PMMA) standards.

\subsection{Preparation of Mesoporous Metal Oxides}

One hundred ninety six milligrams of polymer were dissolved in $800 \mu \mathrm{L}$ of a saturated aqueous solution of aluminum nitrate $\left(1.9 \mathrm{~mol} \mathrm{~L}^{-1}\right)$ or magnesium nitrate $\left(4.9 \mathrm{~mol} \mathrm{~L} \mathrm{~L}^{-1}\right)$. The $\mathrm{Al}\left(\mathrm{NO}_{3}\right)_{3}$-containing solution was treated at $60^{\circ} \mathrm{C}$ with a vapor of an aqueous ammonia solution $(12.5 \%)$ for $3 \mathrm{~h}$ to convert $\mathrm{Al}\left(\mathrm{NO}_{3}\right)_{3}$ to $\mathrm{Al}(\mathrm{OH})_{3} / \mathrm{AlO}(\mathrm{OH})$; the resulting material was dried overnight at $60{ }^{\circ} \mathrm{C}$ and then calcined in a tube furnace for $4 \mathrm{~h}$ at $500{ }^{\circ} \mathrm{C}$ (heating rate $1{ }^{\circ} \mathrm{C} \mathrm{min}-1$ ) to form $\mathrm{Al}_{2} \mathrm{O}_{3}$ and to combust the polymer. The $\mathrm{Mg}\left(\mathrm{NO}_{3}\right)_{2}$-containing solution was dried overnight at $120^{\circ} \mathrm{C}$; the resulting material was calcined in a tube furnace for $2 \mathrm{~h}$ at $300^{\circ} \mathrm{C}$ and for $2 \mathrm{~h}$ at $500{ }^{\circ} \mathrm{C}$ (heating rate $\left.1{ }^{\circ} \mathrm{C} \mathrm{min}^{-1}\right)$ to convert $\mathrm{Mg}\left(\mathrm{NO}_{3}\right)_{2}$ to $\mathrm{MgO}$ and to combust the polymer.

\section{Results and Discussion}

A variety of four simple water soluble polymers were used as porogenic structure directors for mesoporous $\mathrm{Al}_{2} \mathrm{O}_{3}$ and $\mathrm{MgO}$. The polymers possess different hydrophilicity and distinct ability to coordinate to $\mathrm{Al}^{3+}$ and $\mathrm{Mg}^{2+}$ metal cations: (i) poly(ethylene glycol) (PEG; ether groups), (ii) poly(vinyl alcohol) (PVA; hydroxyl groups), (iii) poly(dimethylacrylamide) (PDMAAm; tertiary amido groups), and (iv) poly(N-(2-hydroxypropyl) methacrylamide) (PHPMA; secondary amido with hydroxyl groups). The latter two polymers were synthesized by free-radical polymerization, as shown in Figure 1b,c. Their properties are summarized in Table 2; molecular weights, dispersities, and yields are typical of free-radical polymerization synthesis.

$$
\text { (1,4-dioxane, AlBN }
$$

Figure 1. Synthesis of (a) monomer N-(2-hydroxypropyl) methacrylamide (HPMA) and homopolymers (b) PDMAAm and (c) PHPMA.

The aim of this study was to investigate the impact of the polymers on the porosity of the metal oxides. For this purpose, the respective polymer was dissolved in a saturated aqueous 
solution of aluminum nitrate, followed by treatment in ammonia vapor at $60{ }^{\circ} \mathrm{C}$ to convert $\mathrm{Al}\left(\mathrm{NO}_{3}\right)_{3}$ to $\mathrm{Al}(\mathrm{OH})_{3} / \mathrm{AlO}(\mathrm{OH})$, as described in the experimental section. After evaporation of the water, the material was then calcined at $500{ }^{\circ} \mathrm{C}$ to turn $\mathrm{Al}(\mathrm{OH})_{3} / \mathrm{AlO}(\mathrm{OH})$ into $\mathrm{Al}_{2} \mathrm{O}_{3}$ and simultaneously combust the polymer. For $\mathrm{MgO}$, the same procedure was applied, but without the ammonia treatment step; magnesium nitrate was directly converted to magnesium oxide by calcination. By this procedure, a composite of the metal oxide precursor $\left(\mathrm{Al}(\mathrm{OH})_{3} / \mathrm{AlO}(\mathrm{OH})\right.$ or $\mathrm{Mg}\left(\mathrm{NO}_{3}\right)_{2}$, respectively) and the polymer was formed first, with the polymer being entangled within the inorganic phase. Then, simultaneous conversion of the precursor into the metal oxide and thermal combustion of the polymer led to a mesoporous product.

To study the calcination/polymer combustion step in some detail, thermogravimetric analysis (TGA) was carried out. As an example, the TGA curves of the $\mathrm{Al}(\mathrm{OH})_{3} / \mathrm{PDMAAm}$ composite and of the pure PDMAAm polymer were compared and are shown in Figure 2. A mass loss of ca. 72\% can be observed for the composite material in the temperature range up to $230{ }^{\circ} \mathrm{C}$, which can be attributed to both the dehydration of $\mathrm{Al}(\mathrm{OH})_{3} / \mathrm{AlO}(\mathrm{OH})$ (i.e., $\mathrm{Al}_{2} \mathrm{O}_{3}$ formation) and the combustion of the polymer. Further mass loss of ca. $14 \%$ can be observed between 230 and $570{ }^{\circ} \mathrm{C}$. By comparison, the pure polymer shows an initial mass loss of $6 \%$ below $200{ }^{\circ} \mathrm{C}$, probably due to loss of residual water, then a mass loss of about $74 \%$ between 300 to $400{ }^{\circ} \mathrm{C}$, followed by another $18 \%$ up to ca. $600{ }^{\circ} \mathrm{C}$. Obviously, the presence of the aluminum hydroxide/oxide led to a combustion of the polymer at lower temperature; this effect has already been observed for the combustion of amorphous carbon $[18,26]$ and organic hydrogel matrices [35]. Very similar results were obtained for $\mathrm{Al}_{2} \mathrm{O}_{3}$ prepared using the other polymers (see Figures S1-S3).

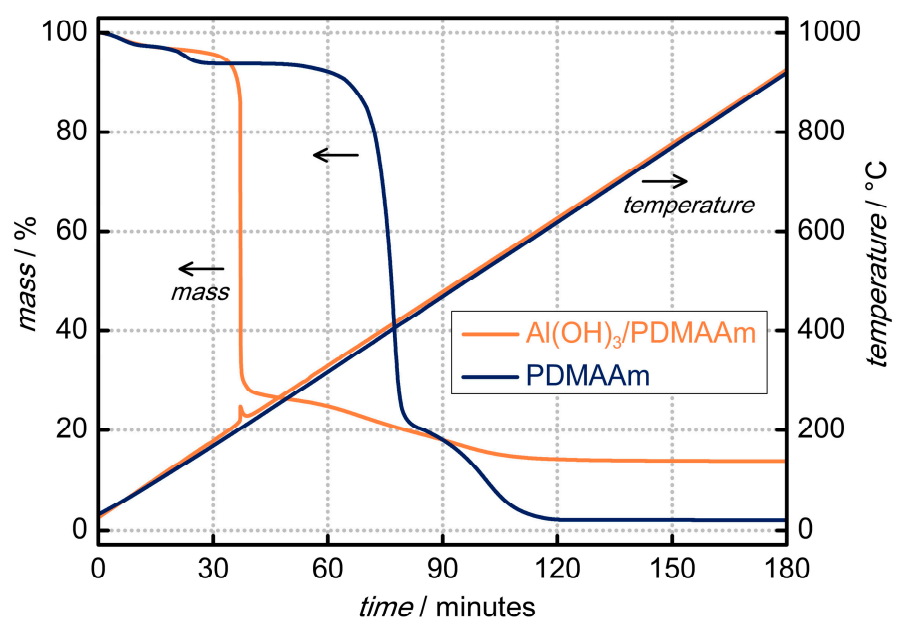

Figure 2. Thermo-gravimetric analysis (TGA) of the $\mathrm{Al}(\mathrm{OH})_{3}$-polymer composite and of the pure polymer PDMAAm.

The porogenic impact of the polymers on the polymer-free metal oxides was confirmed by $\mathrm{N}_{2}$ physisorption analysis. Figure 3 (left) shows the sorption isotherms of four $\mathrm{Al}_{2} \mathrm{O}_{3}$ materials prepared with different polymers. All isotherms exhibit a faint type-IV(a) behavior [43] with a more or less well-pronounced hysteresis. This indicates mesopores with an ill-defined shape, but with a fairly uniform size, as confirmed in the $\mathrm{BJH}$ pore size distribution curves [41] derived from the isotherms (Figure 3, right). Pore widths from 3 to $8 \mathrm{~nm}$ can be observed, with a clear peak occurring at $3.6 \mathrm{~nm}$ in all materials. The pore size distribution is somewhat narrower in the two samples prepared with PVA and PEG, respectively. The specific pore volumes and BET surface areas are shown in Table 2, confirming that a reproducible synthesis of porous alumina with a large surface area up to $365 \mathrm{~m}^{2} \mathrm{~g}^{-1}$ is possible by the utilization of these polymers as porogens. Comparison of all prepared $\mathrm{Al}_{2} \mathrm{O}_{3}$ materials reveals similar mesopore sizes, mesopore volumes, and specific BET areas. The choice of the porogenic polymer matrix has little impact on the porosity. Although polymers with different 
binding sites were used, the appearance of a polymer rich phase due to physical network formation in concentrated solution can be considered the sole reason for pore formation.
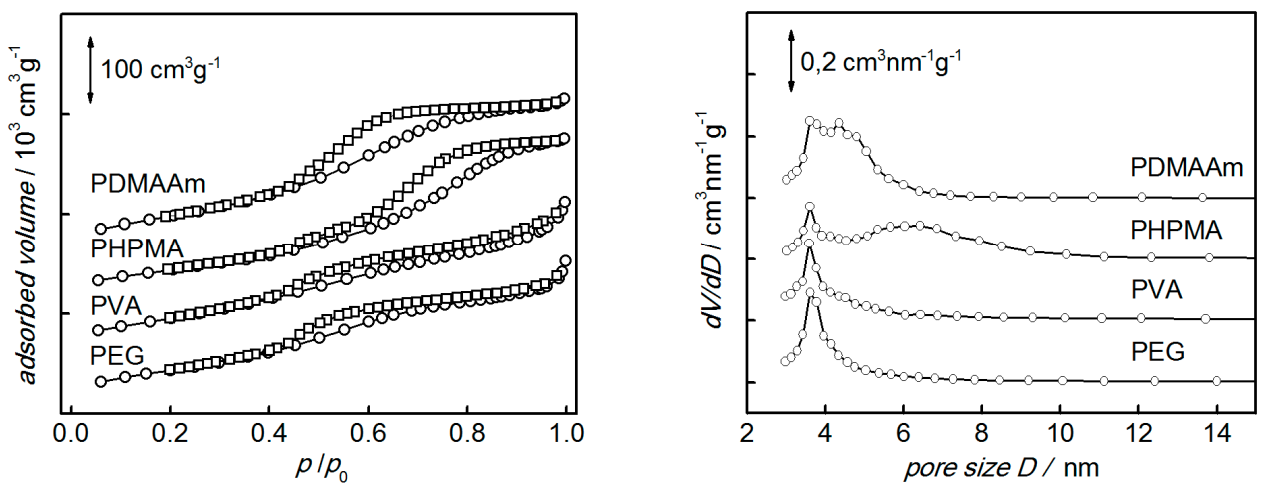

Figure 3. $\mathrm{N}_{2}$ physisorption isotherm (left) and pore size distribution (right) of mesoporous $\gamma-\mathrm{Al}_{2} \mathrm{O}_{3}$ prepared using various polymers as the porogenic structure matrices as indicated. (Data are vertically shifted for clarity).

Table 2. Specific Brunauer-Emmett-Teller (BET) surface areas $A_{\mathrm{BET}}$, pore volumes $V$, and mean pore widths $r$ obtained from $\mathrm{N}_{2}$ physisorption of mesoporous alumina synthesized using various polymers.

\begin{tabular}{cccc}
\hline Polymer Used & $A_{\text {BET }} / \mathbf{m}^{\mathbf{2}} \mathbf{g}^{-\mathbf{1}}$ & $V / \mathbf{c m}^{\mathbf{3}} \mathbf{g}^{-\mathbf{1}}$ & $r / \mathbf{n m}$ \\
\hline PDMAAm & 365 & 0.51 & 3.6 \\
PHPMA & 312 & 0.54 & 3.6 \\
PEG & 325 & 0.44 & 3.6 \\
PVA & 343 & 0.48 & 3.6 \\
\hline
\end{tabular}

Figure 4 shows the powder X-ray diffraction patterns of the alumina materials. Again, the differences between the materials are rather low. All samples exhibit only a few broad reflections, two of which can be attributed to the cubic defect spinel structure of $\gamma-\mathrm{Al}_{2} \mathrm{O}_{3}$. (JCPDS card number 75-0921). The formation of this phase with low crystallinity is commonly observed for $\mathrm{Al}_{2} \mathrm{O}_{3}$ syntheses under these conditions $[17,18]$. The crystallite sizes calculated by the Scherrer method are between 5 and $6 \mathrm{~nm}$.

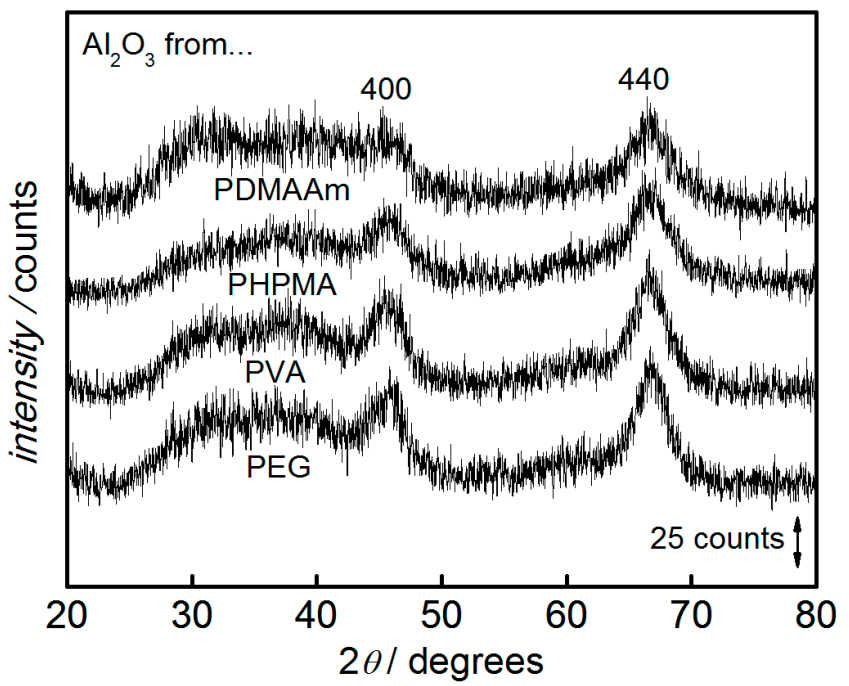

Figure 4. Powder XRD patterns of mesoporous $\gamma-\mathrm{Al}_{2} \mathrm{O}_{3}$ prepared using various polymers as the porogenic structure matrices as indicated. (Data are vertically shifted for clarity). 
Since the choice of polymer turned out not to have any significant impact on the $\mathrm{Al}_{2} \mathrm{O}_{3}$ synthesis, only one polymer, PDMAAm, was chosen for the preparation of porous MgO. The TGA curves of the $\mathrm{Mg}\left(\mathrm{NO}_{3}\right)_{2} /$ PDMAAm composite and of the pure PDMAAm polymer are shown in Figure 5 . For the composite, the mass loss occurs in two distinct steps: by ca. $54 \%$ up to a temperature of $265^{\circ} \mathrm{C}$ and by another $32 \%$ between 265 and $500{ }^{\circ} \mathrm{C}$. It is fair to assume that the first step is mainly attributable to the conversion of magnesium nitrate into magnesium oxide, while the second step corresponds mostly to the polymer decomposition. This seems likely because the pure polymer starts to combust only above ca. $300{ }^{\circ} \mathrm{C}$ (after some initial mass loss of $6 \%$ below $200{ }^{\circ} \mathrm{C}$, presumably due to loss of residual water); a steep reduction in mass by ca. $74 \%$ occurs between 300 and $400{ }^{\circ} \mathrm{C}$, followed by another $18 \%$ between 400 and $600{ }^{\circ} \mathrm{C}$. Again, the presence of the magnesium species results in a polymer decomposition at a slightly lower temperature, although this effect is less pronounced than in the case of the aluminum species.

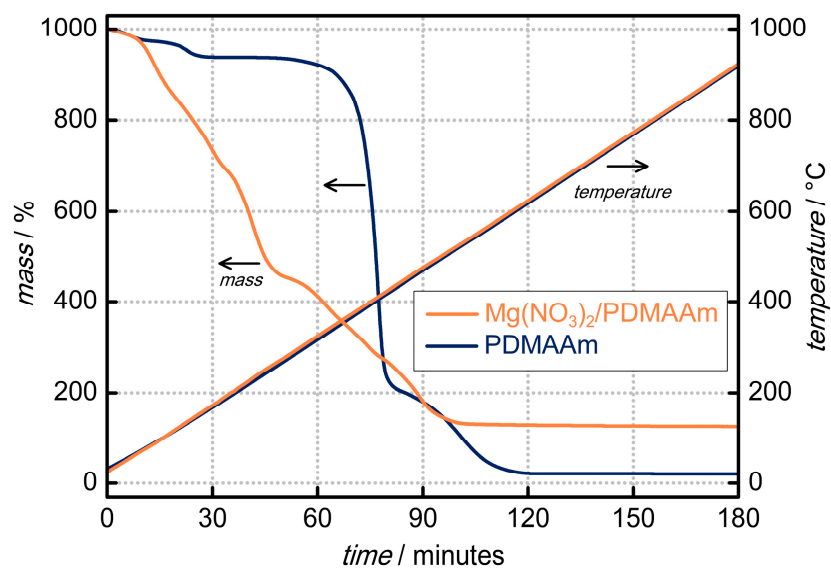

Figure 5. Thermo-gravimetric analysis (TGA) of the $\mathrm{Mg}\left(\mathrm{NO}_{3}\right)_{2}$-polymer composite and of the pure PDMAAm polymer.

Figure 6 shows the $\mathrm{N}_{2}$ physisorption data of the porous $\mathrm{MgO}$ sample. The isotherm shape is mostly type II, with a slight type-IV character and little hysteresis, indicating a fairly low degree of porosity. Accordingly, the pore size distribution peak is very low in intensity. The specific BET surface area and pore volume are $111 \mathrm{~m}^{2} \mathrm{~g}^{-1}$ and $0.37 \mathrm{~cm}^{3} \mathrm{~g}^{-1}$, respectively. Obviously, the polymer failed to have a pronounced porogenic impact in the case of $\mathrm{MgO}$, which may be explained by the sintering of $\mathrm{MgO}$ particles during calcination upon combustion of the polymer. During the $\mathrm{Al}_{2} \mathrm{O}_{3}$ synthesis, by contrast, a solid network of $\mathrm{Al}(\mathrm{OH})_{3} / \mathrm{AlO}(\mathrm{OH})$ was formed before the combustion of the polymer.
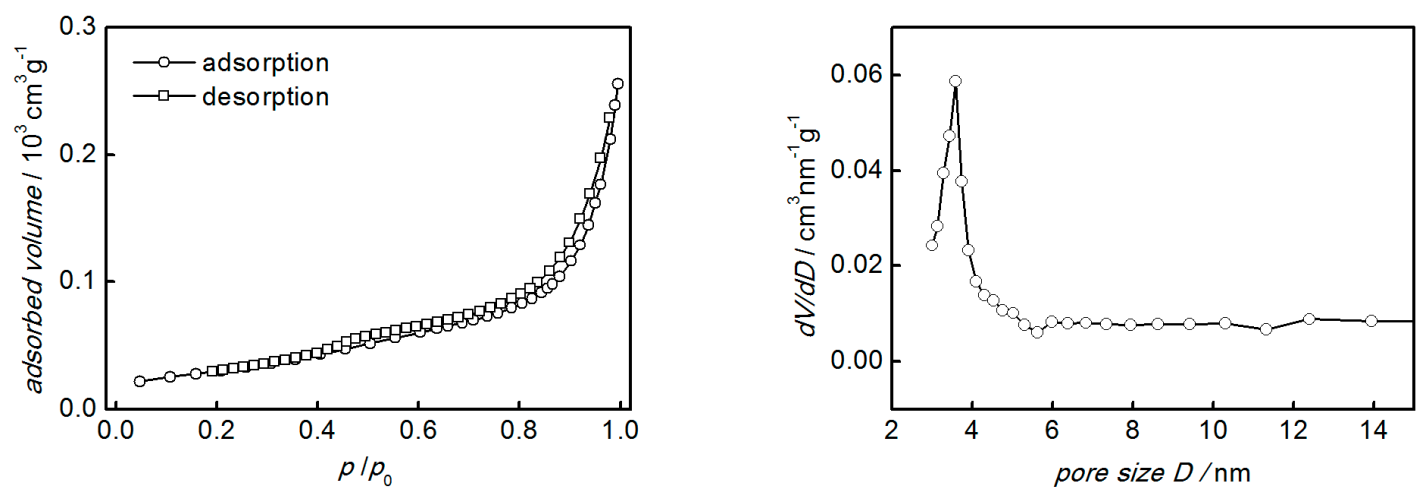

Figure 6. $\mathrm{N}_{2}$ physisorption isotherm (left) and pore size distribution (right) of $\mathrm{MgO}$ prepared using PDMAAm polymer as the porogenic structure matrix. 
The powder X-ray diffraction diagram of $\mathrm{MgO}$ is shown in Figure 7, confirming the cubic rock salt structure of $\mathrm{MgO}$ (JCPDS card number 77-2179) with a substantially higher degree of crystallinity than in case of $\mathrm{Al}_{2} \mathrm{O}_{3}$. This is consistent with the above-made assumption of strong sintering upon polymer combustion. The crystallite size calculated by the Scherrer method is ca. $12 \mathrm{~nm}$.

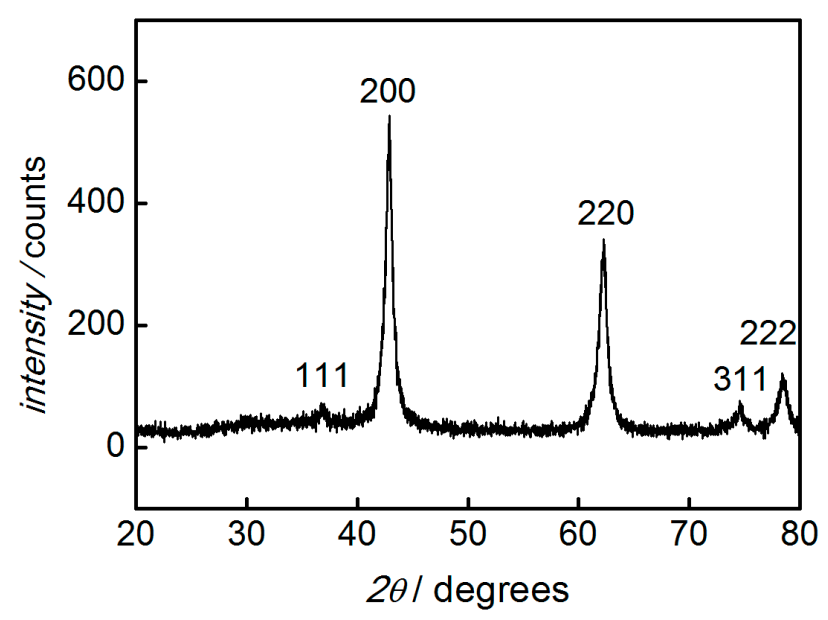

Figure 7. Powder XRD pattern of $\mathrm{MgO}$ prepared by using PDMAAm polymer as the porogenic structure matrix.

\section{Conclusions}

Mesoporous $\gamma-\mathrm{Al}_{2} \mathrm{O}_{3}$ and mesoporous $\mathrm{MgO}$ with large specific BET surface areas were successfully synthesized using simple polymers (PEG, PVA, PDMAAm, and PHPMA) as porogenic matrices under relatively mild conditions. The polymers were mixed with a metal nitrate solution. The polymer matrices were removed by thermal combustion, while the metal oxides were formed at the same time. The mesoporous alumina products exhibit mesopore sizes in the range from 3.6 to $6.4 \mathrm{~nm}$, large specific BET surface areas up to $365 \mathrm{~m}^{2} \mathrm{~g}^{-1}$, and specific pore volumes up to $0.54 \mathrm{~cm}^{3} \mathrm{~g}^{-1}$. Variation of the polymer has little impact on the structural properties of the products. The mesoporous magnesium oxide product has a mesopore size of $3.6 \mathrm{~nm}$, a specific BET surface area of $111 \mathrm{~m}^{2} \mathrm{~g}^{-1}$, and a specific pore volume of $0.37 \mathrm{~cm}^{3} \mathrm{~g}^{-1}$. The calcination of the polymer/metal oxides composite materials benefits from the fact that polymer decomposition is catalyzed by the freshly formed metal oxides.

Supplementary Materials: The following are available online at http://www.mdpi.com/2227-9717/5/4/70/s1. Figure S1: TGA of the $\mathrm{Al}(\mathrm{OH})_{3}-\mathrm{PVA}$ composite and of the pure polymer PVA; Figure S2: TGA of the $\mathrm{Al}(\mathrm{OH})_{3}$-PHPMA composite and of the pure polymer PHPMA; Figure S3: TGA of the $\mathrm{Al}(\mathrm{OH})_{3}-\mathrm{PEG}$ composite and of the pure PEG.

Acknowledgments: The authors thank Manuel Traut for help with the TGA measurements.

Author Contributions: M.T. and D.K. conceived and designed the experiments; Z.C. performed the experiments; Z.C. and C.W. analyzed the data; Z.C., M.T. and D.K. wrote the paper.

Conflicts of Interest: The authors declare no conflict of interest.

\section{References}

1. Tüysüz, H.; Schüth, F. Ordered Mesoporous Materials as Catalysts. Adv. Catal. 2012, 55, 127-239.

2. Li, W.; Liu, J.; Zhao, D. Mesoporous materials for energy conversion and storage devices. Nat. Rev. Mater. 2016, 1, 16023. [CrossRef]

3. Tiemann, M. Porous metal oxides as gas sensors. Chem. Eur. J. 2007, 13, 8376-8388. [CrossRef] [PubMed]

4. Wagner, T.; Haffer, S.; Weinberger, C.; Klaus, D.; Tiemann, M. Mesoporous materials as gas sensors. Chem. Soc. Rev. 2013, 42, 4036-4053. [CrossRef] [PubMed] 
5. Sing, K.S.W.; Everett, D.H.; Haul, R.A.W.; Moscou, L.; Pierotti, R.A.; Rouquérol, J.; Siemieniewska, T. Reporting physisorption data for gas/solid systems with special reference to the determination of surface area and porosity. Pure Appl. Chem. 1985, 57, 603-619. [CrossRef]

6. Gu, D.; Schüth, F. Synthesis of non-siliceous mesoporous oxides. Chem. Soc. Rev. 2014, 43, 313-344. [PubMed]

7. Tiemann, M. Repeated templating. Chem. Mater. 2007, 20, 961-971. [CrossRef]

8. Ren, Y.; Ma, Z.; Bruce, P.G. Ordered mesoporous metal oxides: Synthesis and applications. Chem. Soc. Rev. 2012, 41, 4909-4927. [PubMed]

9. Deng, X.; Chen, K.; Tüysüz, H. Protocol for the nanocasting method: Preparation of ordered mesoporous metal oxides. Chem. Mater. 2017, 29, 40-51.

10. Čejka, J. Organized mesoporous alumina: Synthesis, structure and potential in catalysis. Appl. Catal. A Gen. 2003, 254, 327-338.

11. Choudary, B.M.; Mulukutla, R.S.; Klabunde, K.J. Benzylation of aromatic compounds with different crystallites of MgO. J. Am. Chem. Soc. 2003, 125, 2020-2021. [CrossRef] [PubMed]

12. Trueba, M.; Trasatti, S.P. $\gamma$-Alumina as a support for catalysts: A review of fundamental aspects. Eur. J. Inorg. Chem. 2005, 17, 3393-3403. [CrossRef]

13. Morris, S.M.; Fulvio, P.F.; Jaroniec, M. Ordered mesoporous alumina-supported metal oxides. J. Am. Chem. Soc. 2008, 130, 15210-15216. [CrossRef] [PubMed]

14. Rajagopalan, S.; Koper, O.; Decker, S.; Klabunde, K.J. Nanocrystalline metal oxides as destructive adsorbents for organophosphorus compounds at ambient temperatures. Chem. Eur. J. 2002, 8, 2602-2607. [CrossRef]

15. Li, L.; Wen, X.; Fu, X.; Wang, F.; Zhao, N.; Xiao, F.; Wie, W.; Sun, Y. MgO/ $\mathrm{Al}_{2} \mathrm{O}_{3}$ Sorbent for $\mathrm{CO}_{2}$ Capture. Energy Fuels 2010, 24, 5773-5780. [CrossRef]

16. Wie, J.; Ren, Y.; Luo, W.; Sun, Z.; Cheng, X.; Li, Y.; Deng, Y.; Elzatahry, A.A.; Al-Dahyan, D.; Zhao, D. Ordered mesoporous alumina with ultra-large pores as an efficient absorbent for selective bioenrichment. Chem. Mater. 2017, 29, 2211-2217.

17. Liu, Q.; Wang, A.; Wang, X.; Zhang, T. Ordered crystalline alumina molecular sieves synthesized via a nanocasting route. Chem. Mater. 2006, 18, 5153-5155. [CrossRef]

18. Haffer, S.; Weinberger, C.; Tiemann, M. Mesoporous $\mathrm{Al}_{2} \mathrm{O}_{3}$ by nanocasting: Relationship between crystallinity and mesoscopic order. Eur. J. Inorg. Chem. 2012, 2012, 3283-3288. [CrossRef]

19. Roggenbuck, J.; Tiemann, M. Ordered mesoporous magnesium oxide with high thermal stability synthesized by exotemplating using CMK-3 carbon. J. Am. Chem. Soc. 2005, 127, 1096-1097. [CrossRef] [PubMed]

20. Roggenbuck, J.; Koch, G.; Tiemann, M. Synthesis of mesoporous magnesium oxide by CMK-3 carbon structure replication. Chem. Mater. 2006, 18, 4151-4156. [CrossRef]

21. Waitz, T.; Tiemann, M.; Klar, P.J.; Sann, J.; Stehr, J.; Meyer, B.K. Crystalline ZnO with an enhanced surface area obtained by nanocasting. Appl. Phys. Lett. 2007, 90, 123108. [CrossRef]

22. Wagner, T.; Waitz, T.; Roggenbuck, J.; Fröba, M.; Kohl, C.-D.; Tiemann, M. Ordered mesoporous ZnO for gas sensing. Thin Solid Films 2007, 515, 8360-8363. [CrossRef]

23. Chernikov, A.; Horst, S.; Waitz, T.; Tiemann, M.; Chatterjee, S. Photoluminescence properties of ordered mesoporous ZnO. J. Phys. Chem. C 2011, 115, 1375-1379. [CrossRef]

24. Polarz, S.; Orlov, A.V.; Schüth, F.; Lu, A.-H. Preparation of High-Surface-Area Zinc Oxide with Ordered Porosity, Different Pore Sizes, and Nanocrystalline Walls. Chem. Eur. J. 2007, 13, 592-597. [CrossRef] [PubMed]

25. Roggenbuck, J.; Waitz, T.; Tiemann, M. Synthesis of Mesoporous Metal Oxides by Structure Replication: Strategies of Impregnating Porous Matrices with Metal Salts. Microporous Mesoporous Mater. 2008, 113, 575-582. [CrossRef]

26. Weinberger, C.; Roggenbuck, J.; Hanss, J.; Tiemann, M. Synthesis of Mesoporous Metal Oxides by Structure Replication: Thermal Analysis of Metal Nitrates in Porous Carbon Matrices. Nanomaterials 2015, 5, 1431-1441. [CrossRef] [PubMed]

27. Llusar, M.; Pidol, L.; Roux, C.; Pozzo, J.L.; Sanchez, C. Templated Growth of Alumina-Based Fibers through the Use of Anthracenic Organogelators. Chem. Mater. 2002, 14, 5124-5133. [CrossRef]

28. Jiu, J.; Kurumada, K.; Tanigaki, M. Preparation of oxide with nano-scaled pore diameters using gel template. J. Non-Cryst. Solids 2003, 325, 124-132. [CrossRef] 
29. Kurumada, K.; Suzuki, A.; Baba, S.; Otsuka, E. Relationship between polarity of template hydrogel and nanoporous structure replicated in sol-gel-derived silica matrix. J. Appl. Polym. Sci. 2009, 114, 4085-4090. [CrossRef]

30. Cui, X.; Tang, S.; Zhou, H. Mesoporous alumina materials synthesized in different gel templates. Mater. Lett. 2013, 98, 116-119. [CrossRef]

31. Jiang, R.; Zhu, H.-Y.; Chen, H.-H.; Yao, J.; Fu, Y.-Q.; Zhang, Z.-Y.; Xu, Y.-M. Effect of calcination temperature on physical parameters and photocatalytic activity of mesoporous titania spheres using chitosan/poly(vinyl alcohol) hydrogel beads as a template. Appl. Surf. Sci. 2014, 319, 189-196. [CrossRef]

32. Kuckling, D.; Hoffmann, J.; Plötner, M.; Ferse, D.; Kretschmer, K.; Adler, H.-J.P.; Arndt, K.-F.; Reichelt, R. Photo cross-linkable poly( $N$-isopropylacrylamide) copolymers III: micro-fabricated temperature responsive hydrogels. Polymer 2003, 44, 4455-4462. [CrossRef]

33. Döring, A.; Birnbaum, W.; Kuckling, D. Responsive hydrogels-structurally and dimensionally optimized smart frameworks for applications in catalysis, micro-system technology and material science. Chem. Soc. Rev. 2013, 40, 7391-7420. [CrossRef] [PubMed]

34. Birnbaum, W.; Weinberger, C.; Schill, V.; Haffer, S.; Tiemann, M.; Kuckling, D. Synthesis of mesoporous alumina through photo cross-linked poly(dimethylacrylamide) hydrogels. Colloid Polym. Sci. 2014, 292, 3055-3060. [CrossRef]

35. Weinberger, C.; Chen, Z.; Birnbaum, W.; Kuckling, D.; Tiemann, M. Photo-cross-linked polydimethylacrylamide hydrogels as porogens for mesoporous alumina. Eur. J. Inorg. Chem. 2017, 2017, 1026-1031. [CrossRef]

36. Cottet, H.; Gareil, P. Electrophoretic behavior of fully sulfonated polystyrenes in capillaries filled with entangled polymer solutions. J. Chromatogr. Coruña 1997, 772, 369-384. [CrossRef]

37. Daoud, M.; Stanley, H.E.; Stauffer, D. Scaling, Exponents, and Fractal Dimensions. In Physical Properties of Polymers Handbook, 2nd ed.; Mark, J.E., Ed.; Springer: New York, NY, USA, 2007; pp. 83-92.

38. Brunauer, S.; Emmett, P.H.; Teller, E. Adsorption of gases in multimolecular layers. J. Am. Chem. Soc. 1938, 60, 309-319. [CrossRef]

39. Barrett, E.P.; Joyner, L.G.; Halenda, P.P. The determination of pore volume and area distributions in porous substances. I. Computations from nitrogen isotherms. J. Am. Chem. Soc. 1951, 73, 373-380. [CrossRef]

40. Rowe, M.D.; Chang, C.C.; Thamm, D.H.; Kraft, S.L.; Harmon, J.F.; Vogt, A.P.; Sumerlin, B.S.; Boyes, S.G. Tuning the magnetic resonance imaging properties of positive contrast agent nanoparticles by surface modification with RAFT polymers. Langmuir 2009, 25, 9487-9499. [CrossRef] [PubMed]

41. Kuckling, D.; Harmon, M.E.; Frank, C.W. Photo-cross-linkable PNIPAAm copolymers. 1. Synthesis and characterization of constrained temperature-responsive hydrogel layers. Macromolecules 2002, 35, 6377-6383. [CrossRef]

42. Javadi, A. Synthesis of Thin Hydrogel Layers Based on Photo-Cross-Linkable Polymers. Ph.D. Thesis, Tarbiat Moallem University, Tehran, Iran, May 2012.

43. Thommes, M.; Kaneko, K.; Neimark, A.V.; Olivier, J.P.; Rodriguez-Reinoso, F.; Rouquerol, J.; Sing, K.S.W. Physisorption of gases, with special reference to the evaluation of surface area and pore size distribution (IUPAC technical report). Pure Appl. Chem. 2015, 87, 1051-1069. [CrossRef]

(c) 2017 by the authors. Licensee MDPI, Basel, Switzerland. This article is an open access article distributed under the terms and conditions of the Creative Commons Attribution (CC BY) license (http://creativecommons.org/licenses/by/4.0/). 